\title{
Vitamin D Status and the Effect of Oral Vitamin D Treatment in Children with Alopecia Areata
}

\author{
Karaguzel $\mathbf{G}^{1^{*}}$, Sakarya $\mathrm{NP}^{2}$, Bahadır $\mathrm{S}^{3}$, Beyhun $\mathrm{E}^{4}$ and Yaman $\mathrm{S}^{5}$
}

${ }^{1}$ Department of Pediatric Endocrinology, School of Medicine, Karadeniz Technical University, Trabzon, Turkey

${ }^{2}$ Department of Pediatrics, School of Medicine, Karadeniz Technical University, Trabzon, Turkey

${ }^{3}$ Department of Dermatology, School of Medicine, Karadeniz Technical University, Trabzon, Turkey

${ }^{4}$ Department of Public Health, School of Medicine, Karadeniz Technical University, Trabzon, Turkey

${ }^{5}$ Department of Biochemistry, School of Medicine, Karadeniz Technical University, Trabzon, Turkey

*Corresponding author: Karaguzel G, Department of Pediatric Endocrinology, School of Medicine, Karadeniz Technical University, Trabzon, Turkey, Tel: +90 462 3775924; E-mail: gkaraguzel@ktu.edu.tr

Received date: December 22, 2017; Accepted date: January 15, 2018; Published date: January 20, 2018

Copyright: (ㄷ 2018 Karaguzel G, et al. This is an open-access article distributed under the terms of the Creative Commons Attribution License, which permits unrestricted use, distribution, and reproduction in any medium, provided the original author and source are credited.

\section{Abstract}

Objectives: Little is known about the association of vitamin D and alopecia areata (AA). Our objectives were to search a relation between 25-hydroxyvitamin $D[25(\mathrm{OH}) \mathrm{D}]$ levels and the development of AA and the efficacy of oral vitamin $D$ treatment in children with $A A$ and vitamin $D$ deficiency.

Methods: Thirty newly diagnosed AA patients and 30 sex- and age-matched controls were included in the study. Levels of $25(\mathrm{OH}) \mathrm{D}$, parathormone, calcium, inorganic phosphate, alkaline phosphatase were measured at baseline and sixth month. Both patients and controls who diagnosed vitamin D deficiency were treated with oral vitamin $D$ for six months.

Results: Serum $25(\mathrm{OH}) \mathrm{D}$ levels of the patients and controls were $25.3 \pm 19.4 \mathrm{ng} / \mathrm{ml}$ and $21.3 \pm 12.5 \mathrm{ng} / \mathrm{ml}$, respectively $(p>0.05)$. The frequency of vitamin $D$ deficiency was similar in patients and controls. Serum levels of $25(\mathrm{OH}) \mathrm{D}$ and calcium were increased significantly after six months of the treatment in both patients and controls with vitamin $D$ deficiency $(p<0.05)$. A higher frequency $(47 \%)$ of complete improvement was observed in patients with $A A$ and vitamin $D$ deficiency during oral vitamin $D$ treatment.

Conclusions: There was no statistically significant difference in $25(\mathrm{OH}) \mathrm{D}$ levels between the patients with AA and controls. However, we observed a higher frequency of complete improvement in these patients with an improved vitamin D status. Thus, oral vitamin D treatment can be given only to selected AA patients who are also deficient in vitamin $\mathrm{D}$.

Keywords Vitamin D; Alopecia areata; 25-Hydroxyvitamin D; Vitamin D deficiency

\section{Introduction}

Alopecia areata (AA) is a common immune-mediated non-scarring hair loss disorder that can involve any hair-bearing area. Loss of the growing hair shaft has been related to lymphocytic infiltration on which CD4+ T-cells constitute the majority of lymphocytes in the hair follicule site. A predominant Th1 cytokine profile has also been found at the site of AA lesions [1-5].

AA associated with an increased overall risk of autoimmune disorder such as autoimmune thyroiditis, vitiligo, pernisiyoz anemia, type 1 diabetes, lupus erythematosus, myastenia gravis, celiac disease, and polyendocrinopathy syndrome type $1[1,3,4]$. Environmental and genetic factors have also been suspected as contribute to the disease $[1,3,6]$.

It has been reported that vitamin $\mathrm{D}$ plays an important role in cutaneous immune modulation [7-9]. The active form of vitamin D (1,25-dihydroxyvitamin D) acts as an immunomodulator targeting various immune cells such as macrophages, monocytes, dendritic cells as well as $\mathrm{T}$ lymphocytes and B lymphocytes [9-11]. Vitamin D receptors (VDR) are expressed in dermal papilla cells and in the epidermis of the hair follicles. 1,25-dihydroxyvitamin D plays an important role in the development of hair follicle via VDR expression [12]. Furthermore, total or partial alopecia is an important finding of the patients with vitamin D-dependent rickets type II [13].

There are a few studies in adults regarding the role of vitamin D in the pathogenesis of AA and there is only one pediatric study assessing vitamin D level in 20 children with AA [14-16]. The objective of the present study was to search a possible relation between the serum levels of 25-hydroxyvitamin $\mathrm{D}[25(\mathrm{OH}) \mathrm{D}]$ and the development of AA in childhood. We also evaluated prospectively the efficacy of oral vitamin $\mathrm{D}$ treatment on vitamin $\mathrm{D}$ status in children with $\mathrm{AA}$ and vitamin $\mathrm{D}$ deficiency.

\section{Materials and Methods}

This study was carried out in Trabzon (latitude $41^{\circ} \mathrm{N}$ ), northeastern Turkey. Thirty patients (20 girls) aged 6 to 17 years with newlydiagnosed AA from our outpatient Pediatric Endocrinology and 
Dermatology clinics were included consecutively in the study. The participants were excluded if they had any other autoimmune or chronic illness, if they were obese or had been using medication in previous six months that could alter outcome of the study. Controls were 30 sex- and age-matched apparently healthy children (20 girls) with no family history of AA or systemic autoimmune diseases in their first-degree relatives were recruited on the same day as the patients to avoid the effects of the seasonal variation in vitamin D levels.
Topical therapy was started all patients with AA at the beginning of the study (Figure 1). The questionnaire covering general nutrition attitude, time spent outside, and clothing preference was applied and socio-demographic data were obtained.

\section{Patients with alopecia areata}

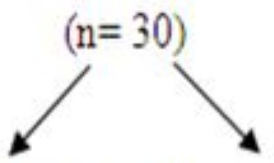

Vitamin D sufficient Vitamin D deficient

$$
\begin{gathered}
\quad(\mathrm{n}=15) \\
\text { Topical therapy } \\
(3 \mathrm{CI}, 20 \%)
\end{gathered}
$$

$$
(\mathrm{n}=15)
$$

Vitamin $\mathrm{D}$ and

topical therapy

$$
(7 \mathrm{CI}, 47 \%)
$$

Total $(n=60)$
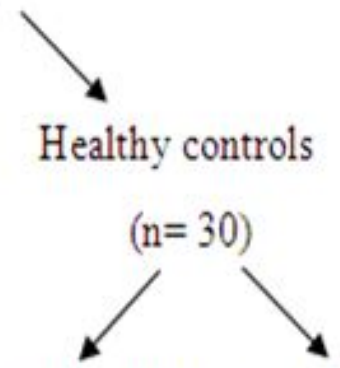

Vitamin D sufficient Vitamin D deficient

$$
(\mathrm{n}=14)
$$

$(\mathrm{n}=16)$

\section{No therapy}

Vitamin D

Figure 1: Distribution of the patients and controls (CI: complete improvement).

Blood samples were obtained in the morning for serum 25(OH)D, calcium, inorganic phosphate, alkaline phosphatase (AP), and parathormone $(\mathrm{PTH})$ measurements at baseline and sixth month for whom vitamin $\mathrm{D}$ deficient. The samples were separated within half an hour and stored at $-80^{\circ} \mathrm{C}$ until analysis. Height and weight of participants were measured and recorded. Body mass index (BMI) was calculated using the formula: weight $(\mathrm{kg}) /$ height $(\mathrm{m})^{2}$. Vitamin D deficiency was defined as serum 25(OH)D levels of $<20 \mathrm{ng} / \mathrm{ml}$. Both patients and controls who were diagnosed vitamin $\mathrm{D}$ deficient were treated with vitamin $\mathrm{D}$ for six months with a dose of $1500 \mathrm{IU} /$ day vitamin $\mathrm{D}$ was given if the serum $25(\mathrm{OH}) \mathrm{D}$ level $<20 \mathrm{ng} / \mathrm{ml}$ and 3000 $\mathrm{IU} /$ day if the level $<10 \mathrm{ng} / \mathrm{ml}$. Informed written consent was obtained from the parents. The study was approved by our Institutional Ethics Committee (No: 2011/110).

\section{Laboratory measurements}

Serum 25(OH)D levels were assessed by high-performance liquid chromotography (HPLC with reversed phase column, IC3401rp, Thermo Seperator Products, Immuchrom GmBH, Germany). The intraassay coefficient of variations (CVs) were $2.6 \%$ at $22.6 \mathrm{ng} / \mathrm{ml}$ and $1.5 \%$ at $41.9 \mathrm{ng} / \mathrm{ml}$, the inter-assay CVs were $4 \%$ at $21.6 \mathrm{ng} / \mathrm{ml}$ and $3.6 \%$ at $42.2 \mathrm{ng} / \mathrm{ml}$. Intact PTH was measured using a 2-site chemiluminescence enzyme-labeled immunometric assay (Immulite 2000 Siemens, LA, USA) with the upper limit of normal was $65 \mathrm{pg} / \mathrm{ml}$.
Serum calcium, inorganic phosphate, and AP were measured using colorimetric methods (Cobas 8000, Roche Diagnostic, Manheim, Germany). Secondary hyperparathyroidism was defined as a serum $\mathrm{PTH}>65 \mathrm{pg} / \mathrm{ml}$ and a serum calcium $<10.5 \mathrm{mg} / \mathrm{dl}$.

\section{Statistical analyses}

Data were analyzed by using SPSS for Windows (SPSS, Inc, Chicago, IL). Results were expressed as mean \pm standard deviation or percentages. The normality of the distribution of each variable was determined using the Kolmogorov-Simirnov test. Data comparisons of means between two groups were performed with student's t-tests after testing for normality. Paired-sample t-test was used to compare the dependent variables after testing for normality. The chi-square analysis was used to compare categorical data. Pearson's correlation was used in correlation analyses of the variables. Statistically significance was set at $\mathrm{p}<0.05$.

\section{Results}

Twenty (66\%) of the patients with AA in the study were girls and $34 \%$ of them were boys. Serum $25(\mathrm{OH}) \mathrm{D}$ levels were not significantly different between the patients and controls. The baseline clinical and biochemical characteristics of the patients and controls were similar (Table 1). 
Page 3 of 4

\begin{tabular}{|l|l|l|l|}
\hline Parameters & Patients $(\mathbf{n}=\mathbf{3 0})$ & Controls $(\mathbf{n}=\mathbf{3 0})$ & $\mathbf{P}^{*}$ \\
\hline Girls/Boys $(\mathrm{n})$ & $20 / 10$ & $20 / 10$ & NS \\
\hline Age (years) & $10.5 \pm 2.9$ & $10.5 \pm 2.8$ & NS \\
\hline Body mass index $\left(\mathrm{kg} / \mathrm{m}^{2}\right)$ & $17.9 \pm 2.2$ & $17.4 \pm 2.1$ & NS \\
\hline 25(OH)D $(\mathrm{ng} / \mathrm{ml})$ & $25.3 \pm 19.4$ & $21.3 \pm 12.5$ & NS \\
\hline Calcium $(\mathrm{mg} / \mathrm{dl})$ & $9.6 \pm 0.3$ & $9.7 \pm 0.4$ & NS \\
\hline Phosphorus $(\mathrm{mg} / \mathrm{dl})$ & $4.6 \pm 0.4$ & $4.5 \pm 0.7$ & NS \\
\hline Alkaline phosphatase $(\mathrm{U} / \mathrm{l})$ & $212 \pm 81$ & $202 \pm 64$ & NS \\
\hline Parathormone $(\mathrm{pg} / \mathrm{ml})$ & $51.0 \pm 29.6$ & $42.2 \pm 29.9$ & NS \\
\hline
\end{tabular}

Table 1: Clinical and laboratory characteristics of the patients with alopecia areata and Controls at baseline (mean $\pm \mathrm{SD}$ ).

The frequency of vitamin D deficiency was similar in patients (50\%) and controls (53\%). Hyperparathyroidism was found only $27 \%(\mathrm{n}=4)$ of AA patients with vitamin D deficiency at baseline. Serum $25(\mathrm{OH}) \mathrm{D}$ levels were increased and PTH levels were decreased significantly after six months of treatment with oral vitamin $\mathrm{D}$ in AA patients. In controls, 25(OH)D levels were increased significantly at sixth month.

None of the children had hyperparathyroidism or hypercalcemia at the end of the study. Any new lesion did not develop during the treatment in the patients who were vitamin $\mathrm{D}$ deficient. We observed complete improvement in 10 patients with AA, seven of whom were vitamin $\mathrm{D}$ deficient and received combination treatment with oral vitamin D and topical treatment in Figure 1 . There was no statistically significant relation between serum levels of $25(\mathrm{OH}) \mathrm{D}$ and the general nutrition attitude, time spent outside or clothing preference (data not shown). We did also did not find any correlation between BMI and 25(OH)D levels ( $\mathrm{p}>0.05)$ (Table 2).

\begin{tabular}{|l|l|l|l|}
\hline Parameters & Baseline & $\mathbf{6}^{\text {th }}$ Month & $\mathbf{P}^{*}$ \\
\hline 25(OH)D3 (ng/ml) & \multicolumn{3}{|l|}{} \\
\hline Patients $^{\theta}$ & $10.5 \pm 2.9$ & $25.5 \pm 12.4$ & $<0.001$ \\
\hline Controls & $11.5 \pm 5.1$ & $30.4 \pm 16.4$ & $<0.001$ \\
\hline
\end{tabular}

Parathormone (pg/ml)

\begin{tabular}{|l|l|l|l|}
\hline Patients $^{\theta}$ & $68.0 \pm 31.0$ & $47.0 \pm 15.0$ & $<0.05$ \\
\hline Controls & $52.4 \pm 35.9$ & $48.2 \pm 32.9$ & NS \\
\hline
\end{tabular}

Calcium(mg/dl)

\begin{tabular}{|l|l|l|l|}
\hline Patients $^{\theta}$ & $9.6 \pm 0.3$ & $9.8 \pm 0.2$ & $<0.001$ \\
\hline Controls & $9.8 \pm 0.4$ & $9.6 \pm 0.4$ & $<0.005$ \\
\hline
\end{tabular}

${ }^{*} \mathrm{P}$ values of $<0.05$ statistically significant; $\theta$ vs. controls, all of the comparison $p>0.05$; NS: non-significant

Table 2: Serum levels of 25-hydroxyvitamin D, parathormone, and calcium in patients $(n=15)$ and controls $(n=16)$ who were vitamin $D$ deficient.

\section{Discussion}

The study results showed that serum $25(\mathrm{OH}) \mathrm{D}$ levels were not significantly different between the children with AA and the sex- and age-matched healthy controls both at the time of diagnosis and sixth month. Oral vitamin D treatment improved vitamin D status in both patients and controls with vitamin D deficiency. It is well known that low 25(OH)D levels are associated with increased PTH levels. At the end of the present study, none of the patients had hyperparathyroidism supporting that the doses of vitamin $\mathrm{D}$ treatment for vitamin $\mathrm{D}$ deficient children were adequate. To our knowledge, this is the first prospective study to compare serum $25(\mathrm{OH}) \mathrm{D}$ levels in patients with AA and healthy controls in childhood. It was reported only in a seven year-old patient with AA treated with topical calcipotriol [17]. There are also a few studies regarding the relationship between serum 25(OH)D levels and AA [14-16,18].

We determined that vitamin $\mathrm{D}$ deficiency is a frequent problem among the patients with AA as well as healthy controls. This finding was not surprising for us because the prevalence of vitamin D deficiency was found $93 \%$ in spring and $71 \%$ in autumn in healthy school-children in our previous study [19]. Studies investigating the association between hypovitaminosis $\mathrm{D}$ and $\mathrm{AA}$ have yielded conflicting results $[14,15,18]$. In a cross-sectional study from Turkey, 42 adults with AA and healthy controls were analyzed in terms of $25(\mathrm{OH}) \mathrm{D}$ levels and found that $25(\mathrm{OH}) \mathrm{D}$ levels were significantly lower in patients than that of controls [14]. There is no national vitamin $\mathrm{D}$ fortification program in Turkey and the difference could be related to the extent of sunlight exposure during outdoor physical activities in their study area which geographically located at south of Turkey (latitude $36^{\circ} \mathrm{N}$ ). As a similar finding to ours, d'Ovidio et al. reported that the frequency of vitamin $\mathrm{D}$ deficiency in patients with AA was not significantly different from controls [15]. They also reported that decreased level of $25(\mathrm{OH}) \mathrm{D}$ was not correlated with extent of hair loss. In a recent study from Israel, 25(OH)D levels were evaluated in 23 adult patients with AA and controls $(n=20)$ [18]. The authors reported that vitamin D levels were significantly lower in patients than those controls and suggested vitamin D deficiency could be a risk factor for AA occurrence. However, their study group was relatively small and they did not exclude obese patients or the patients who treated with vitamin D that could have influence upon $25(\mathrm{OH}) \mathrm{D}$ levels.

The active form of vitamin $\mathrm{D}$ mediates its action by binding to specific VDR located in the nucleus of target cells. It has been demonstrated that VDR is strongly expressed in the key structures of human and murine hair follicles [9,20]. A lack of VDR could be associated with reduced epidermal differentiation and hair follicle growth [21]. We did not find any difference between the patients with AA and controls in terms of $25(\mathrm{OH}) \mathrm{D}$ levels during six months suggesting that vitamin D deficiency is not a significant risk factor for AA occurrence. Further trials with a large number of patients are needed to confirm these results.

In this study, no statistically significant difference was observed in the serum $25(\mathrm{OH}) \mathrm{D}$ levels between the patients with AA and the controls however, we observed that the oral vitamin $\mathrm{D}$ treatment improves hair regrowth with the higher frequency of complete improvement in patients with AA and vitamin D deficiency. The finding support the thought that oral vitamin $\mathrm{D}$ treatment can be given only to selected AA patients who are also deficient in vitamin D. 
Citation: Karaguzel G, Sakarya NP, Bahadir S, Beyhun E, Yaman S (2018) Vitamin D Status and the Effect of Oral Vitamin D Treatment in Children with Alopecia Areata. J Steroids Horm Sci 9: 189. doi:10.4172/2157-7536.1000189

Page 4 of 4

\section{Author Contributions}

Karaguzel G contributed to the study design, study conduct, data collection, data analysis and interpretation and manuscript preparation. Sakarya NP, Beyhun E, Bahadır S and Yaman S contributed to the study design, data collection and analysis.

\section{Conflict Of Interest}

All authors declare no conflict of interest.

\section{Funding}

This study was supported by Karadeniz Technical University Research Project Unit under protocol No: 2010.114.003.08.

\section{References}

1. Fricke ACV, Miteva M (2015) Epidemiology and burden of alopecia areata: A systematic review. Clin Cosmet Investig Dematol 8: 397-403.

2. Gilhar A, Paus R, Kalish RS (2007) Lymphocytes, neuropeptides, and genes involved in alopecia areata. J Clin Invest 117: 2019-2027.

3. Goh C, Finkel M, Christos PJ, Sinha AA (2006) Profile of 513 patients with alopecia areata: Associations of disease subtypes with atopy autoimmune disease and positive family history. J Eur Acad Dermatol Venereol 20: 1055-1060

4. Islam N, Leung PSC, Huntley AC, Gerswin ME (2015) The autoimmune basis of alopecia areata: A comprehensive review. Autoimmun Rev 14 81-89.

5. MacLean KJ, Tidman MJ (2013) Alopecia areata: More than skin deep Practitioner 257: 29-32.

6. McDonagh AJ, Tazi-Ahnini R (2002) Epidemiology and genetics of alopecia areata. Clin Exp Dermatol 27: 405-409.

7. Reichrath J (2000) Vitamin D and the hair follicle. In: Kragballe K, ed. The Vitamin D in Dermatology. New York: Marcel Dekker.

8. Ghoreishi M, Bach P, Obst J, Komba M, Fleet JC, et al. (2009) Expansion of antigen-specific regulatory $\mathrm{T}$ cells with the topical vitamin $\mathrm{D}$ analog calcipotriol. J Immunol 182: 6071-6078.
9. Chen CH, Sakai Y, Demay MB (2001) Targeting expression of the human vitamin D receptor to the keratinocytes of vitamin D receptor null mice prevents alopecia. Endocrinology 142: 5386-5389.

10. Nancy AL, Yehuda S (2009) Prediction and prevention of autoimmune skin disorders. Arch Dermatol Res 301: 57-64.

11. Sato-Deguchi E, Imafuku S, Chou B, Ishii K, Hiromatsu K, et al. (2012) Topical vitamin $\mathrm{D}_{3}$ analogues induce thymic stromal lymphopoietin and cathelicidin in psoriatic skin lesions. Br J Dermatol 167: 77-84.

12. Baeke F, Takiishi T, Korf H, Gysemans C, Mathieu C (2010) Vitamin D: Modulator of the immune system. Curr Opin Pharmacol 10: 482-496.

13. Bergman R, Schein-Goldshmid R, Hochberg Z, Ben-Izhak O, Sprecher E (2005) The alopecias associated with vitamin D-dependent rickets type IIA and with hairless gene mutations: A comparative clinical, histologic, and immunohistochemical study. Arch Dermatol 141: 343-351.

14. Yilmaz N, Serarslan G, Gokce C (2012) Vitamin D concentrations are decreased in patients with alopecia areata. Vitam Trace Elem 1:105-109.

15. d'Ovidio R, Vessio M, d'Ovidio FD (2013) Reduced levels of 25hydroxyvitamin $\mathrm{D}$ in chronic/relapsing alopecia areata. Dermatoendocrinol 5: 271-273.

16. Unal M, Gonulalan G (2017) Serum vitamin D is related to disease severity in pediatric alopecia areata. J Cosmet Dermatol.

17. Kim DH, Lee JW, Kim IS, Choi SY, lim YY (2012) Successful treatment of alopecia areata with topical calcipotriol. Ann Dermatol 24: 341-344.

18. Mahamid M, Abu-Elhija O, Samamra M, Mahamid A, Nseir W (2014) Association between vitamin D levels and alopecia areata. Isr Med Assoc J 16: 367-370.

19. Karaguzel G, Dilber B, Can G, Okten A, Deger O, et al. (2014) Seasonal vitamin $\mathrm{D}$ status of healthy school children and predictors of low vitamin D status. J Pediatr Gastroenterol Nutr 58: 654-660.

20. Aoi N, Inoue K, Chikanishi T, Fujiki R, Yamamoto H, et al. (2012) 1 1 ,25dihydroxyvitamin D3 modulates the hair-inductive capacity of dermal papilla cells: Therapeutic potential for hair regeneration. Stem Cells Transl Med 1: 615-626.

21. Xie Z, Komuves L, Yu QC, Elalieh H, Nq DC, et al. (2002) Lack of the vitamin $\mathrm{D}$ receptor is associated with reduced epidermal differentiation and hair follicle growth. J Invest Dermatol 118: 11-16. 